Pass wear resi st ance for per pendi cul ar recor di ng medi a

\begin{tabular}{|l|l|}
\hline 著者 & $\begin{array}{l}\text { Tagami Kat sumi chi, Tamai H., Hayashi da H. , } \\
\text { Ar ai Toyoko }\end{array}$ \\
\hline $\begin{array}{l}\text { j our nal or } \\
\text { publ i cat i on t i tl e }\end{array}$ & I EEE Transact i ons on Nagnet i cs \\
\hline vol une & 24 \\
\hline number & 6 \\
\hline page range & $2655-2657$ \\
\hline year & $1988-11-01$ \\
\hline URL & ht t p: //hdl . handl e. net /2297/17571 \\
\hline
\end{tabular}




\section{PASS WEAR RESISTANCE FOR PERPENDICULAR RECORDING MEDIA}

K. Tagami, H. Tamai, H. Hayashida and T. Arai

Microelectronics Res. Labs. NEC Corporation

Mi yazaki 4-chome Mi yamae-ku, Kawasaki, 213 Japan

Abstract - Pass wear resistance for sputtered $\mathrm{CoCr}$ perpendicular flexible disks has been investigated. The flexible disk was composed of $\mathrm{CoCr}$ film on heat resistant base film, protection layer and lubricant. The disk pass wear durabilities were evaluated by conventional double-sided 3.5 inch flexible disk drive. Pass wear strongly depends on $\mathrm{CoCr}$ film preparation conditions. As a result of film scratch test using a sapphire needle, it was found that the scratch depth SD $(\mu \mathrm{m})$ per load force $L F(\mathrm{~g})$ depends on preparation conditions, and that the $\mathrm{CoCr}$ film hardness relates to jass wear durability. SD/LF values range from 0.2 to .3 for $\mathrm{CoCr}$ films without a protection layer. By Forming the protection layer and adding a lubricant. the range in SD/LF values vary from $0.2-0.3$ to 0.1 . 0.3 . The disk hardness, especially for small SD/LF media, is improved. A pass wear durability of 30 million passes was attained for the disk having $\mathrm{SD} / \mathrm{LF}=0.1$. It is shown that the media hardness for a disk using flexible film is a very important factor which determines pass wear durability.

\section{INTRODUCTION}

Sputtered $\mathrm{CoCr}$ perpendicular anisotropy films have been intensely investigated for use as very high density flexible disk media [1]. A key factor in technologies to realize $\mathrm{CoCr}$ perpendicular recording is pass wear durabilities. Many efforts have been made to improve the durability. As factors determining the pass wear durability, there are pass wear base films, lubricant, protective layer, head material and so on $[2,3,4,5]$. In addition, $\mathrm{CoCr}$ film mechanical property also is a important factor $[6,7]$.

In these pass wear tests single sided spherical heads have been widely used $[1,4,5,6,7]$. However, pass wear durability [ 3 ] for a double-sided flexible disk drive is needed from the disk memory capacity points of view. The pass wear deterioration of the thin film media is caused by scratching with wear particles and head sliders [8] in flexible disk drive (FDD).

This paper reports on the correlation between media mechanical property and pass wear resistance of a $\mathrm{CoCr}$ flexible disk for double-sided FDD.

\section{SAMPLE PREPARATION AND EXPERIMENTAL}

A flexible disk was composed of lubricant, protection layer and $\mathrm{CoCr}$ film $(0.3 \mu \mathrm{m}$ thick) on heat resistant base film ( $30 \mu \mathrm{m}$ thick). Figure 1 shows 3 dimensional surface roughness for a base film. The average roughness of base film was $24 \mathrm{~A}$. Preparation conditions for the Disks A, B and C are shown in Table 1. The substrate rotation for intermittent sputtering was $6 \mathrm{rpm}$. CoCr films were deposited by $r . f$. magnetron sputtering. Sputtering pressure was $1 \mathrm{~m}$ torr. The lubricant and protective layers $(0.02 \mu \mathrm{m})$ were 1 iquid and inorganic material, respectively. The lubricant and protective layers were prepared for all flexible disks under the same conditions.

To investigate wear characteristics on flexible disks, specimens subject to wear tests were formed into 3.5 inch diameter flexible disks. The pass wear number for disks was measured under the following conditions: 1) 3.5 inch double-sided FDD ( 1 MB ). 2) Rotational speed: $600 \mathrm{rpm} .3$ ) Head slider: calcium titanate. 4) Head pressure: 20 g. 5)Track: 20, 7) Environment:20$30{ }^{\circ} \mathrm{C}, 30-70 \% \mathrm{RH}$.

In order to examine flexible disk strength resistance to scratching by head slider and wear particles the disk scratching strength was

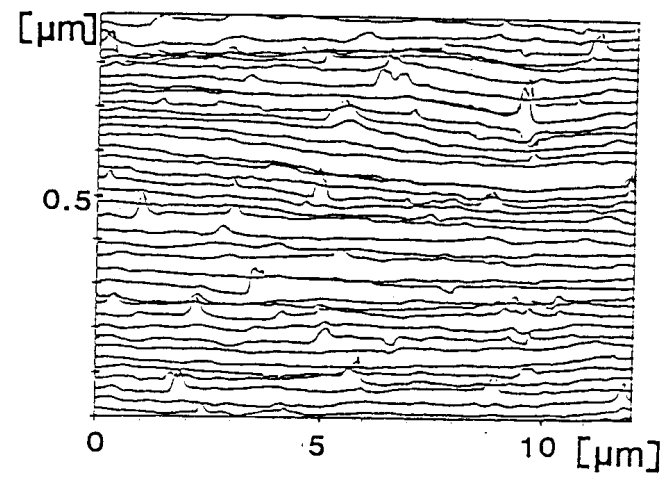

Fig. 1 Three dimensional surface roughness for a flexible disk.

Table 1. Flexible disk preparation conditions

\begin{tabular}{|l|c|l|l|}
\hline $\begin{array}{l}\text { Disk } \\
\text { No. }\end{array}$ & $\begin{array}{c}\text { CoCr film } \\
\text { No. }\end{array}$ & $\begin{array}{c}\text { CoCr } \\
\text { sputtering }\end{array}$ & Temperature \\
\hline A & A & Intermittent (Batch) & $20^{\circ} \mathrm{C}$ \\
\hline B & B & Intermittent (Batch) & $100^{\circ} \mathrm{C}$ \\
\hline C & C & $\begin{array}{l}\text { Continuous } \\
\text { (heat can roll) }\end{array}$ & $100^{\circ} \mathrm{C}$ \\
\hline
\end{tabular}

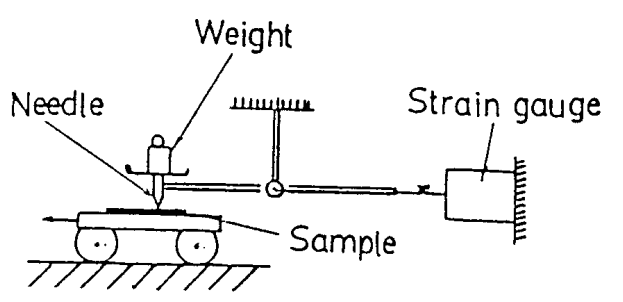

Fig. 2 Configuration of scratching test apparatus.

investigated using a scratching needle. Figure 2 shows the configuration of the scratching test apparatus. The scratching needle was sapphire with $0.025 \mathrm{~mm}$ radius. The needle travel velocity was $50 \mathrm{~mm} / \mathrm{min}$. In the scratching test, scratching depth and scratching force were both measured under temperature $25{ }^{\circ} \mathrm{C}$ and 50-60 $\%$ RH. The scratch depths were calculated from the scratch width and the radius of the spherical tip of the sapphire needle.

\section{RESULTS AND DISCUSSION}

3.1 CoCr films strength effect on pass wear durability Figure 3 shows relative outputs for flexible disks $A, B$ and $C$ (table 1 ) versus pass number. As shown in Fig. 3, the pass wear strongly depends on $\mathrm{CoCr}$ film preparation conditions, under the same lubricant and protective layer conditions. The pass wear durability for $D_{i s k s} A, B$ and $C$ are $<10^{4}$ passes, $1.1 \times 10^{5}$ passes and $>3 \times 10^{7}$ passes, respectively.

In order to clarify the causes, scratching resistant strengths for Cocr films used in flexible disks were examined. Figure 4 shows photo-micrographs 
for regions scoured by scratching needle on CoCr films $A$ and $C$. The scratching width increases with increasing needle load. The scratching width for CoCr film $A$ is greater than that for the $\mathrm{CoCr}$ film C. A part of $\mathrm{CuCr}$ film A was removed from the base film at $20 \mathrm{~g}$ needle load.

Figure 5 shows scratching depth SD versus needle load force LF for $\mathrm{CoCr}$ films $A, B$ and $C . \quad S D$ is proportional to $L F$ in the low $L F$ region. The coefficients $(=\mathrm{SD} / \mathrm{LF})$ are $0.3,0.25$ and 0.2 for $\mathrm{CoCr}$ $A, B$ and $C$, respectively. $\mathrm{CoCr}$ films,prepared by continuous sputtering and high heat treatment have greater film strength than that prepared by intermittent sputtering. The film surface temperature for continuous sputtering is higher than that for intermittent sputtering. Therefore, the magnitude order of film surface temperature for $\mathrm{CoCr} f i l m s \mathrm{~A}, \mathrm{~B}$ and $\mathrm{C}$ is as follows,

$\mathrm{CoCr} \mathrm{C}>\mathrm{CoCr} \mathrm{B}>\mathrm{CoCr} \mathrm{A}$

These results show that the heat applied during sputtering promotes sputtering particle migrations on the $\mathrm{film}$ and improves the film strength. The pass wear durability of the disk increases with the decrease of $\mathrm{SD} / \mathrm{LF}$ value. In the large LF region, the larger SD/LF value is, the larger SD becomes. This means that wear resistances for $\mathrm{CoCr}$ films with large SD/LF values deteriorate, even for small impact forces.

Figure 6 shows friction force versus scratching distance $t$ for $\mathrm{CoCr}$ films $A$ and $C$. The friction force for $\mathrm{CoCr} f \mathrm{ilm} A$, with large $S D / L F$ value, is greater than that of $\mathrm{CoCr}$ film $\mathrm{C}$ with small SD/LF value. Figure 7 shows friction force variation versus $L F$. The friction force variation is due to scratching depth variation and begins with a smaller LF values ( $10 \mathrm{~g}$ )

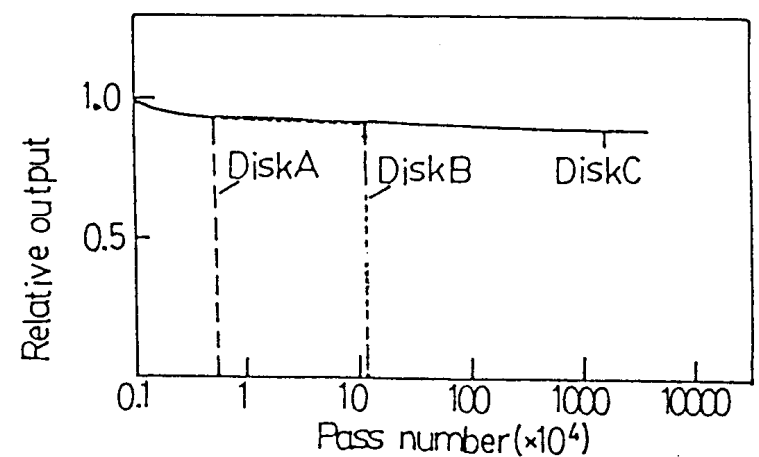

Fig. 3 Relative output versus pass number for flexible disks $A, B$ and $C$.

\section{LF $20 \mathrm{~g}$}

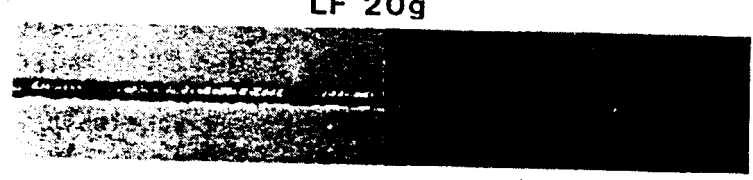

$\mathrm{LF} 30 \mathrm{~g}$

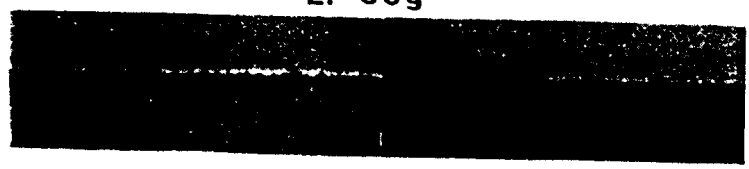

LF 40g

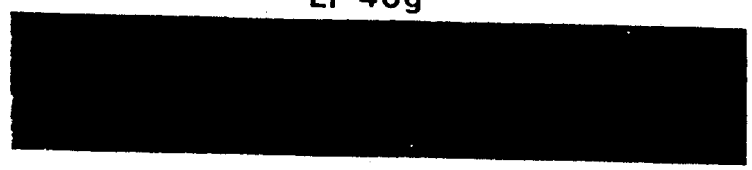

CoCrA

CoCrC

Fig. 4 Photo-micrographs of scoured regions for $\mathrm{CoCr}$ f i $1 \mathrm{~ms} A$ and $C$. for $\mathrm{CoCr}$ film A, as compared with CoCr film C. Figure 8 shows the friction force of scratching needle versus $L F$ for $\mathrm{CoCr}$ films $A, B$ and $C$. The friction forces also increase with increasing LF, as previously shown for $S D$ versus LF in Fig. 5 .

\subsection{Effect of protecttive layyer on gass} Furthermore, to clarify the factor of pass wear durability in 3.1 . Scratching resistance was examined from protective layer points of view.

Figure 9 shows scratching depth versus LF for Disks $A, B$ and $C$ in Table 1 , after coating with protective layer and lubrication. Figure 10 shows photo-micrographs of regions scratched by the needle for Disks $A$ and $C$. By forming protective layer on $\mathrm{CoCr}$ films, SD/LF values for Disks $B$ and $C$ change from 0.2 0.24 to $0.1-0.17$. Media hardness is improved as $\mathrm{CoCr}$ film hardness becomes large. However, the SD/LF values for disk A does not change from SD/LF 0.3 of the $\mathrm{CoCr}$ film without protective layer. Figure 11 shows scratching force variation for Disk $A$ and $C$. As shown in Figs. 10 and 11, abrasive wear for Disk A increases after forming a protective layer on the low hardness $\mathrm{CoCr} \mathrm{film}$. Therefore, these results show that media strength is a very important factor, which determines pass wear resistance margin, and that a pass wear resistance of $30 \mathrm{milli}$ on passes can be attained by using appropriate conditions during media preparation.

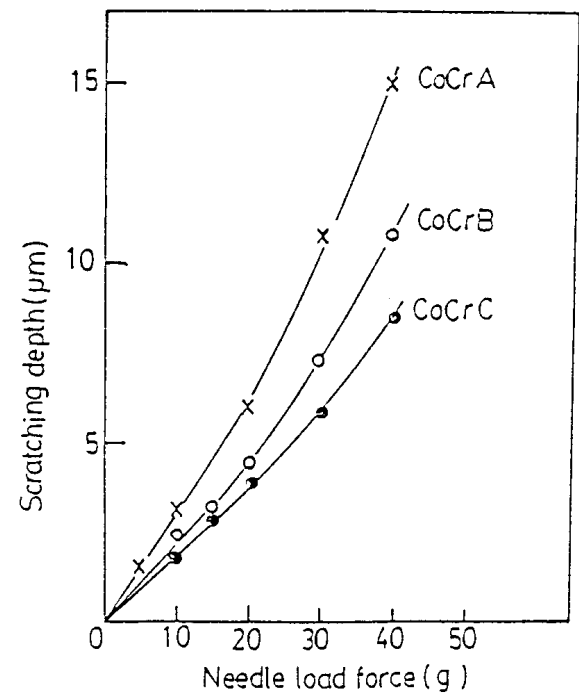

Fig. 5 Scratching depth SD versus needle load force LF for $\mathrm{CoCr}$ films $A, B$ and $C$.

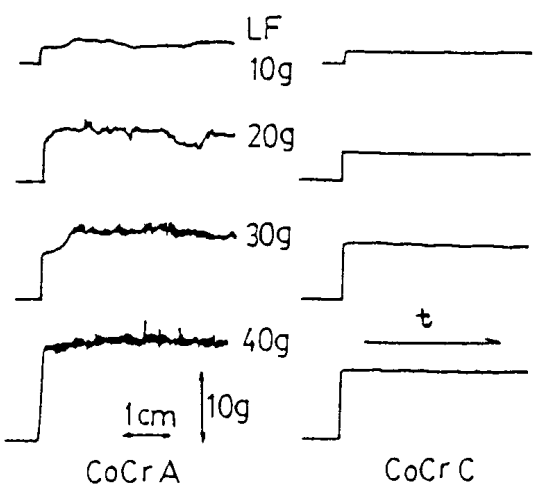

Fig. 6 Friction forces versus scratching distance t for $\operatorname{CoCr}$ films $A$ and $C$. LF values $=10,20,30$ and $40 \mathrm{~g}$. 


\section{CONCLUSION}

Pass wear strongly depends on $\mathrm{CoCr}$ film preparation conditions. As a result of film scratch tests using a sapphire needle, it was found that the scratch depth SD $(\mu \mathrm{m})$ per load force $L F(g)$ relates to pass wear durability. SD/LF values range from 0.2 to 0.3 for CoCr films. By forming the protective layer and adding a lubricant, the SD/LF values vary from $0.2-$ 0.3 to 0.1-0.3. The media hardness is improved, especially for small SD/LF media. The disk pass wear resistance of 30 million passes was attained for a disk with SD/LF 0.1

\section{ACKNOWLEDGMENT}

The authors would like to thank Dr. Esho and Mr.Ito for their encouragement and Mr. Takeda, Mr. Motomura and Mr. Yanagisawa for technical support and suggestions.

\section{REFERENCE}

[1] S. I wasaki and Y. Nakamura, IEEE Trans. Magn., MAG-13, p1272, 1972

[2] P. Buttafava, V. Bretti, G. Ciardiello, M. Piano, G. Caporiccio and A. M. Scarati, IEEE Trans. Magn. MAG-21, 1533 (1985)

[31 M.Nagao, K.Sano, M.Kojima, H.Iwasaki, A.Nahara, T.Ki tamoto, IEEE Trans. Magn. MAG-23, 2395 (1987)

[4] M. Yamaura, T.Yatabe, H.Matsuzawa, S. Kadokura and S.Sobajima, IEEE Trans. Magn. MAG-22, 349 (1986)

[5] Y. Nakatsukasa, H. Tanaka, T. Kyoi zumi and Y. Abe, IEEE Trans. Magn. MAG-22, 1002 (1986)

[6] Y. Motomura and K. Tagami, IECE Tech. Group Meeting of Magnetic Recording, Japan, MR85-5(1985) 3 .

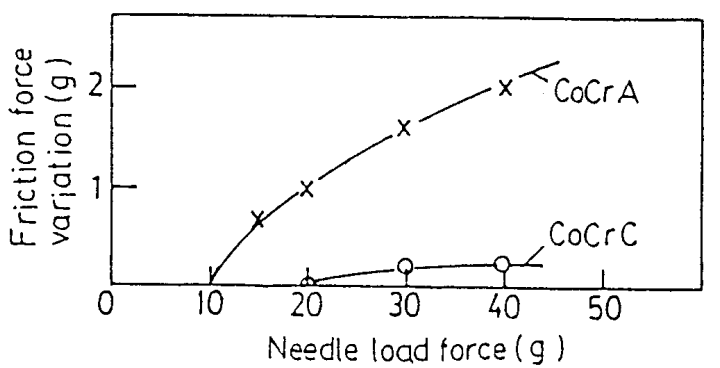

Fig. 7 Friction force variation versus needle load force for $\mathrm{CoCr}$ films $A$ and $C$.

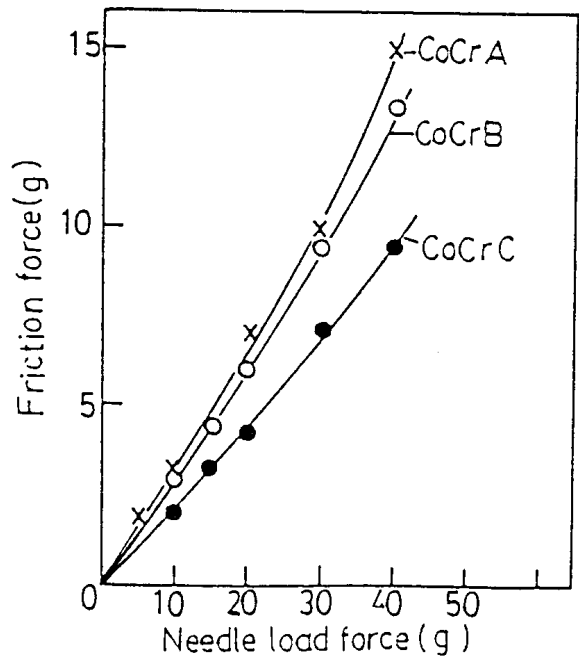

Fig. 8 Friction forces versus scratching needle load force for $\mathrm{CoCr}$ films $\mathrm{A}, \mathrm{B}$ and $\mathrm{C}$.
[7] Y.Motomura and K.Tagami, IEEE Trans. Magn. MAG-22, 346 (1986)

[8] N. Furuya and Y. Nakayama, IEEE Trans. Magn. MAG23, 2401, (1987)

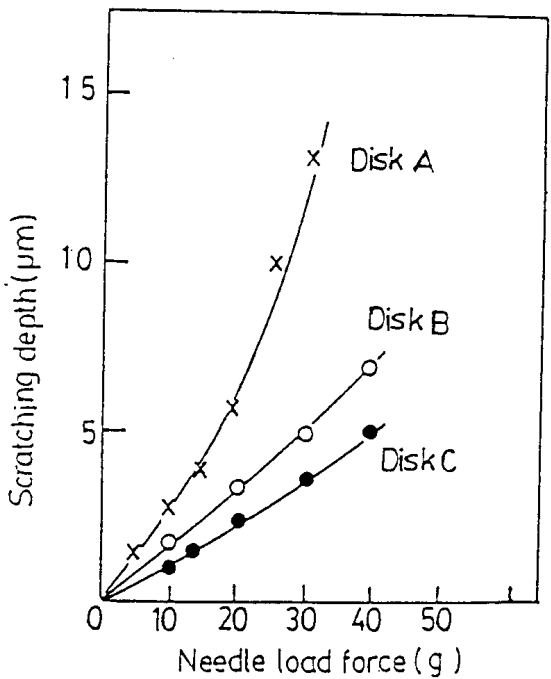

Fig. 9 Scratching depth versus needle load force for disks $A, B$ and $C$ with lubricant and protective overcoat.

LF $20 \mathrm{~g}$

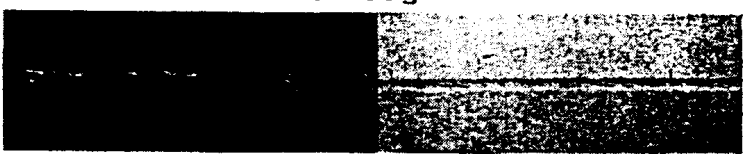

LF $30 \mathrm{~g}$

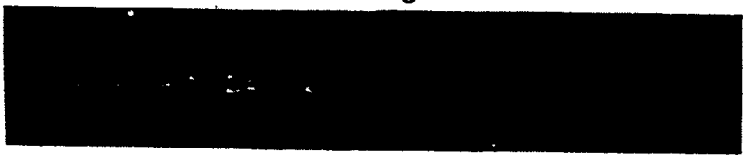

LF $40 \mathrm{~g}$

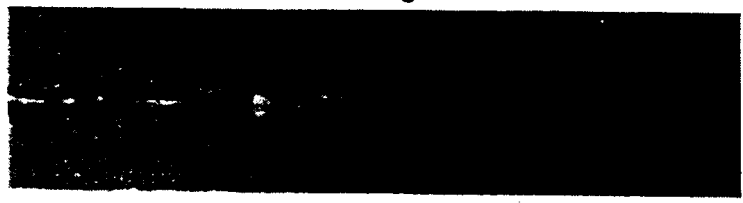

DiskA

Disk C

Fig.10 Photo-micrographs of scoured regions for disks $A$ and $C$ with lubricant and protective overcoat.

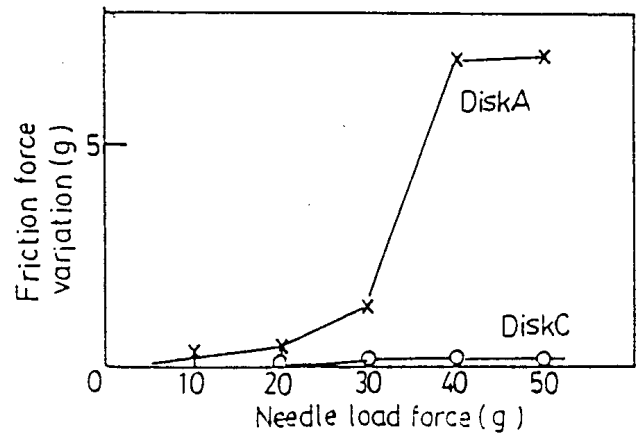

Fig.11 Friction force variation versus needle load force for disks $A$ and $C$ with lubricant and protective overcoat. 